\title{
Global warming accelerates the upfreezing of permafrost in arid middle Tianshan Mountains
}

\author{
LI ChuanChuan, CHEN YiXin, NIE ZhenYu, CUI ZhiJiu \& LIU GengNian* \\ College of Urban and Environmental Sciences, Peking University, Beijing 100871, China
}

Received March 14, 2013; accepted April 24, 2013; published online May 22, 2013

\begin{abstract}
Upfreezing is an important geomorphic process in the periglacial environment. It is a product of cold climate and thus an important part of the cryospheric processes. Based on the long-term positioning observations in the source area of the Urumqi River, this article represents an in-depth discussion of the characteristics of sorted circles and upfreezing mechanisms in the Tianshan Mountains. In the source area of the Urumqi River, the intensity of upfreezing is the highest within the top $25 \mathrm{~cm}$ near the surface, while targets with a diameter of $3 \mathrm{~cm}$ are least affected by upfreezing. There is no distinct difference between the centre with fine grains and the margin with coarse debris within the same sorted circle in terms of the intensity of upfreezing. The correlation analysis demonstrates that temperature plays an important role in upfreezing and the development of sorted circles. A long-time positioning observation of sorted circles reveals that periglacial landforms are sensitive to regional climate change and respond quickly to the temperature increase of the recent two decades. Enhanced upfreezing was found to be due to increased soil moisture content.
\end{abstract}

Tianshan Mountains, sorted circle, upfreezing, climate change

Citation: $\quad$ Li C C, Chen Y X, Nie Z Y, et al. Global warming accelerates the upfreezing of permafrost in arid middle Tianshan Mountains. Chin Sci Bull, 2013, 58: 3806-3814, doi: 10.1007/s11434-013-5891-2

Sorted circles represent a patterned ground in which the mesh is dominantly circular and has a sorted appearance commonly due to a border of stones surrounding finer material [1]. The sorting effects, including the upward and edgewise orienting of stones are mainly due to the upfreezing (also known as frost jacking), which is the motion of objects embedded in soils that undergo frost heave. Previous studies explained the upfreezing of different objects in the active layer, such as stones, glass objects, wood pegs and artifacts, by either the frost-pull or frost-push theory [2-7]. When the ground expands during freezing it carries objects with it, yet when it contracts during thawing, fines adhere to each other and leave objects behind. Repetition of this process would leads to ejection of objects from fines [2]. This kind of hypothesis is called frost-pull. Grawe [8] contend that upfreezing is explained by the greater heat conductivity of objects than fines, whereby ice forms around

*Corresponding author (email: liugn@pku.edu.cn) objects or at their base and forces them up. They suggest that the seeping in of fines during thawing would prevent objects from returning to their original position. The above concept can be called the frost-push hypothesis. Washburn [2] concluded that moisture was the critical control since the greatest heave was associated with wet localities, and both the frost-pull and frost-push mechanisms appear to operate, and probably reinforce each other. Experimental studies have examined upfreezing within mostly ice-rich and frost susceptible sediments [9-11]. The frost-susceptibility of the stone may also be an important factor $[12,13]$. In spite of these studies, the nature of the upfreezing mechanism still remains unclear.

Since 1990, we have laid various positioning observation sites in the source area of the Urumqi River in order to get first-hand data on the mechanism of upfreezing. Combining these with the topographic and meteorological data from this area, we completed an in-depth study on upfreezing in sorted circle, including its characteristics, its developing 
trend, main influential factors, etc. Here we present the process of upfreezing in the mid-latitude arid alpine periglacial environment and its response to global climate change.

\section{Study site}

The Tianshan Mountains, located at the central part of the Eurasian continent, span from $40^{\circ}$ to $44^{\circ} \mathrm{N}$ and stretches from $70^{\circ}$ to $96^{\circ} \mathrm{E}$ (Figure 1). The climate of this area is of a semiarid type, and is dominated by the westerly jet stream.

The study site, namely the source area of the Urumqi River, is located on the north slope of Mt. Kelawucheng $\left(43^{\circ} 06^{\prime} \mathrm{N}, 86^{\circ} 50^{\prime} \mathrm{E}\right)$, in the central Tianshan Mountains. The elevation range of the ridges is $4100-4300 \mathrm{~m}$ a.s.l., with the highest peak being Tianger (4486 $\mathrm{m}$ a.s.l.). The modern snowline is located at $4000-4100 \mathrm{~m}$ a.s.l., and the lower limit of permafrost is $2900-3100 \mathrm{~m}[14,15]$. According to the meteorological data of Dry Cirque, which is located at $3802 \mathrm{~m}$, the annual average temperature of the area was $-6^{\circ} \mathrm{C}$ during 1990-2008, and the annual average precipitation was $405 \mathrm{~mm}$, which occurred mainly during the summer (June-August).

The periglacial zone above $3000 \mathrm{~m}$ in this area has developed various types of patterned ground under suitable topographic and pedologic conditions, which mainly developed at the altitude of 3600-3900 m.

In the early 1980s, Ji [16] analyzed the geomorphic and climatic requirements for the formation of sorted circles, and dated sorted circles on the basis of their morphology, state of preservation and the development of vegetation. Beginning in the 1990s, many studies on the periglacial landforms in the source area of Urumqi River have been done, including repeated measurements, pitting, geophysical exploration, debris fabric, lichen dating and laboratory analyses. The morphology, sorting features, fabric of marginal debris and topographic conditions of the sorted circles has been observed [17-24].

\section{Methods}

Observation sites were set up at the base of the back wall in Dry Cirque, center of Dry Cirque and rock steps of Dry Cirque, which are marked with $\mathrm{A}, \mathrm{B}$, and $\mathrm{C}$ respectively and shown in Figure 1. There are sorted circles distributing in A, B, C sites, which are inside the Dry Cirques. The conditions of sorted circles are shown in Table 1. At each observation site, more than 30 targets of different types of cylindrical wood pegs are hammered into the ground until the top reached the ground surface at different positions. One year later, the amount of protrusion of the stakes was measured with a tape, and then the targets were hammered to the ground level again. Different types of targets are used, which are categorized into targets with different lengths, targets with different diameters, cross targets, and numbered 1,2 , and 3 respectively. The smallest active layer thickness is $1.25 \mathrm{~m}$ in this area [25]. The length of all targets was no more than fifty centimeters in order to ensure the target inserts into the active layer. We observe and record the heaving height of targets at the same time of each year. However the method does not provide the real annual heave amounts, as part of the heave amount must be counteracted by the subsidence of the wood pegs during thaw consolidation; Actual heave must be greater. Thus, the data presented in this paper represents the "minimum" heave amounts.

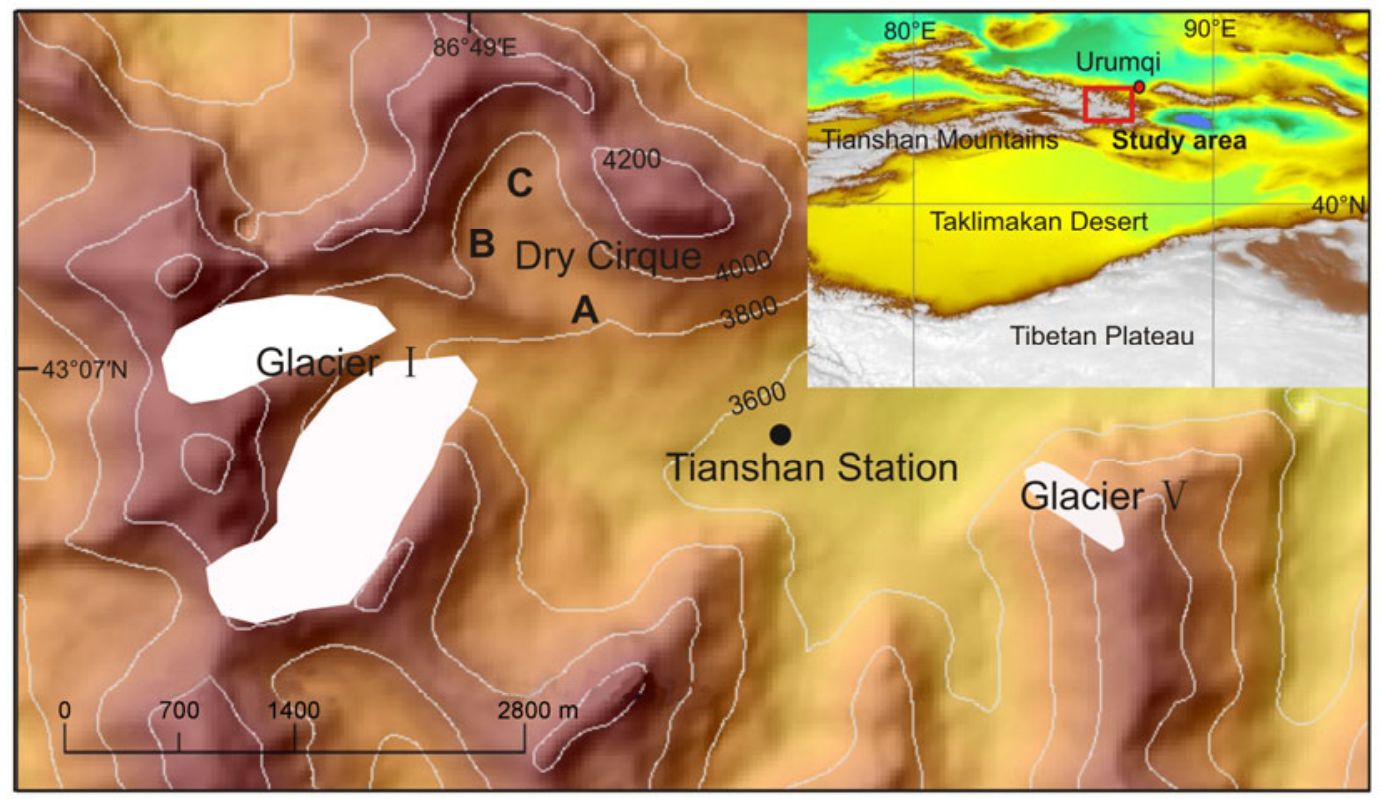

Figure 1 Location of the study area. A, B, and C are observation sites. 
Table 1 Conditions of the different sorted circles in Dry Cirques [22]

\begin{tabular}{cccll}
\hline Sites & Altitude $(\mathrm{m})$ & Age $(\mathrm{ka} \mathrm{BP})$ & \multicolumn{1}{c}{ Shape } & \multicolumn{1}{c}{ Grain size distribution } \\
\hline C & 3950 & $0.4-0.5$ & bread-like & gradually coarser from bottom to top \\
B & 3880 & $2.0-3.5$ & higher center & gradually coarser from top to bottom \\
A & 3820 & $10.0-20.0$ & higher edge & fine and coarse grains mixed \\
\hline
\end{tabular}

\section{Results}

\subsection{Effects of upfreezing with different target lengths}

In order to understand the effects of upfreezing in different depths of sorted circle, we hammered targets with the same diameter (namely $3.5 \mathrm{~cm}$ ) and different lengths $(5,10,15$, $20,25,30,35,40,45$, and $50 \mathrm{~cm}$ ) into the centers of sorted circles of similar scale at A, B, and C sites. This observation covers the period from 1991 to 2011. Due to increased measurements, the average value can better represent realistic movement, we adopt the annual average value can be adopted as the height of upfreezing. In Table 2, the majority of targets with lengths of $5,10,15$, and $20 \mathrm{~cm}$ are heaved out of the ground within a year, so the actual height of upfreezing is far greater than portrayed by the measured data.

Most targets shorter than $15 \mathrm{~cm}$ are heaved out of the ground within one year, and thus the precise heaving heights are unclear, so the minimums of their heaving heights are given instead. The average upfreezing heights of each observation site are as follows: A-1>3.4 cm, B-1>8.6 cm, $\mathrm{C}-1>7.5 \mathrm{~cm}$. As shown in Table 1, the individual annual average heaving heights of targets shorter than $25 \mathrm{~cm}$ in A-1 and targets shorter than $20 \mathrm{~cm}$ in B-1 and C- 1 are almost all greater than the collective averages of each observation site, with the only exception being a high value of the target with a length of $35 \mathrm{~cm}$ in B-1. Considering some imprecise data, we suspect the performance of upfreezing in Dry Cirques is strongest at the depth of $20-25 \mathrm{~cm}$ near the surface. This phenomenon coincides with the results of Schmid [26], who

Table 2 Average annual heave in different depths

\begin{tabular}{rrrr}
\hline \multirow{2}{*}{ Depth $(\mathrm{cm})$} & \multicolumn{3}{c}{ Average annual heave $(\mathrm{cm} / \mathrm{a})$} \\
\cline { 2 - 4 } & A-1 & B-1 & C-1 \\
\hline 5 & $>1.7$ & $>5.0$ & $>5.0$ \\
10 & $>4.8$ & $>9.3$ & $>10.0$ \\
15 & $>4.2$ & $>11.8$ & $>12.9$ \\
20 & 3.5 & 10.3 & 9.2 \\
25 & 3.6 & 7.6 & 6.8 \\
30 & 3.4 & 7.1 & 4.8 \\
35 & - & 9.3 & 5.7 \\
40 & - & 8.0 & 5.7 \\
45 & 3.3 & - & - \\
50 & 3.0 & - & - \\
\hline
\end{tabular}

found that the deeper the peg insertion, the less the heave in Germany. Czeppe [27] found that wood pegs inserted to a depth of $15 \mathrm{~cm}$ were heaved out within a year in Spitsbergen. This phenomenon can be easily understood, since there is a positive correlation between rate of upfreezing and number of freeze-thaw cycles [28]. The shallowest targets had been appreciably heaved by more freeze-thaw cycles. Another factor to consider is following the lift of an object by the frost-pull mechanism, thawing of soil above the bases of the object could lead to collapse of the ground around its upper portions and thus contribute to its upfreezing, which would be very obvious if it is located close to the surface [2].

\subsection{Effects of upfreezing with different target diameters}

Targets with the same length (namely $35 \mathrm{~cm}$ ) but different diameters $(1,2,3,4$, and $5 \mathrm{~cm})$ were inserted into the centers of sorted circles of similar scale at A, B, and C sites to inspect the effects of upfreezing on different target diameters. The observation covers the period from 1991 to 2011. The annual average value was adopted as the height of upfreezing. It was found that targets with a diameter of $3 \mathrm{~cm}$ undergo minimal effects of the upfreezing when compared with targets of other diameters in the same place and same depth (Table 3). The results are consistent at all three observation sites. The overall annual average heights of upfreezing at A-2, B-2, and C-2 observation sites are 3.6, 8.7, and $6.5 \mathrm{~cm}$ respectively, while the targets with a diameter of $3 \mathrm{~cm}$ are heaved 2.6, 7.7, and $4.7 \mathrm{~cm}$ respectively, which are 1,1 , and $1.8 \mathrm{~cm}$ less than their overall averages. With the upfreezing of stones, large stones would tend to heave more than small stones [11]. It is puzzling that the medium diameter $(3 \mathrm{~cm})$ yields minimum heaves. Further work is required to confirm and explain such phenomenon.

Table 3 Average annual heave with different diameters

\begin{tabular}{cccc}
\hline \multirow{2}{*}{$\begin{array}{c}\text { Diameter } \\
(\mathrm{cm})\end{array}$} & \multicolumn{3}{c}{ Average annual heave $(\mathrm{cm} / \mathrm{a})$} \\
\cline { 2 - 4 } & $\mathrm{A}-2$ & $\mathrm{~B}-2$ & $\mathrm{C}-2$ \\
\hline 1 & 4.0 & 9.8 & 7.0 \\
2 & 3.2 & 8.7 & 8.1 \\
3 & 2.6 & 7.7 & 4.7 \\
4 & 5.0 & 8.5 & 5.6 \\
5 & 3.1 & 9.0 & 6.9 \\
\hline
\end{tabular}




\subsection{Effects of upfreezing with different positions in sorted circle}

In order to conduct a more efficient discussion of the effects of upfreezing at different positions within the same sorted circle, especially between fine center and coarse border, we set up A-3, B-3, and C-3 observation points.

A-3 was laid in 1990, which consisted of 15 targets of the same diameter $(3.5 \mathrm{~cm})$ and length $(25 \mathrm{~cm})$ distributed in cross-shaped within a single sorted circle (Figure 2). We categorized the targets into Central targets (numbered 4, 5, 6 ), the inner targets (numbered 3, 12, 7, 13), the outer targets (numbered 2, 11, 8, 14), and Marginal targets (numbered $1,10,9,15)$. The annual average upfreezing heights of these four groups of targets are 4.1, 4.0, 3.1, and $3.6 \mathrm{~cm}$ respectively.

B-3 was laid in 1991, and consisted of 13 targets in the same diameter $(3.5 \mathrm{~cm})$ and length $(30 \mathrm{~cm})$. These targets were also categorized into central targets (numbered 4), the inner targets (numbered 3, 7, 12, 14), the outer targets (numbered 2, 6, 9, 12), and marginal targets (numbered 1, 7, $8,13)$. The annual average upfreezing heights of these four groups of targets are 4.9,5.4, 5.3, and $6.3 \mathrm{~cm}$ respectively.

C-3 was laid in 1992, and consisted of 16 targets in the same diameter $(3.5 \mathrm{~cm})$ and length $(30 \mathrm{~cm})$. The central targets were numbered $4,5,6,13$, the inner targets (numbered $3,7,12,14$ ), the outer targets (numbered 2, 8, 11, 15), and marginal targets (numbered 1, 9, 10, 16). The annual average upfreezing heights of these four groups of targets are $4.1,4.6,1.4$, and $5.4 \mathrm{~cm}$ respectively.

At A-3, the central targets demonstrated the highest level of upfreezing and the inner targets follow in terms of annual averages (Table 4). At B-3 and C-3, the marginal targets get the highest level and the inner targets follow. As the data gives no clear distinction between different positions, the effects of upfreezing were considered to be not significantly affected by the different position of sorted circle. As the grain sizes differ widely between center and border, the
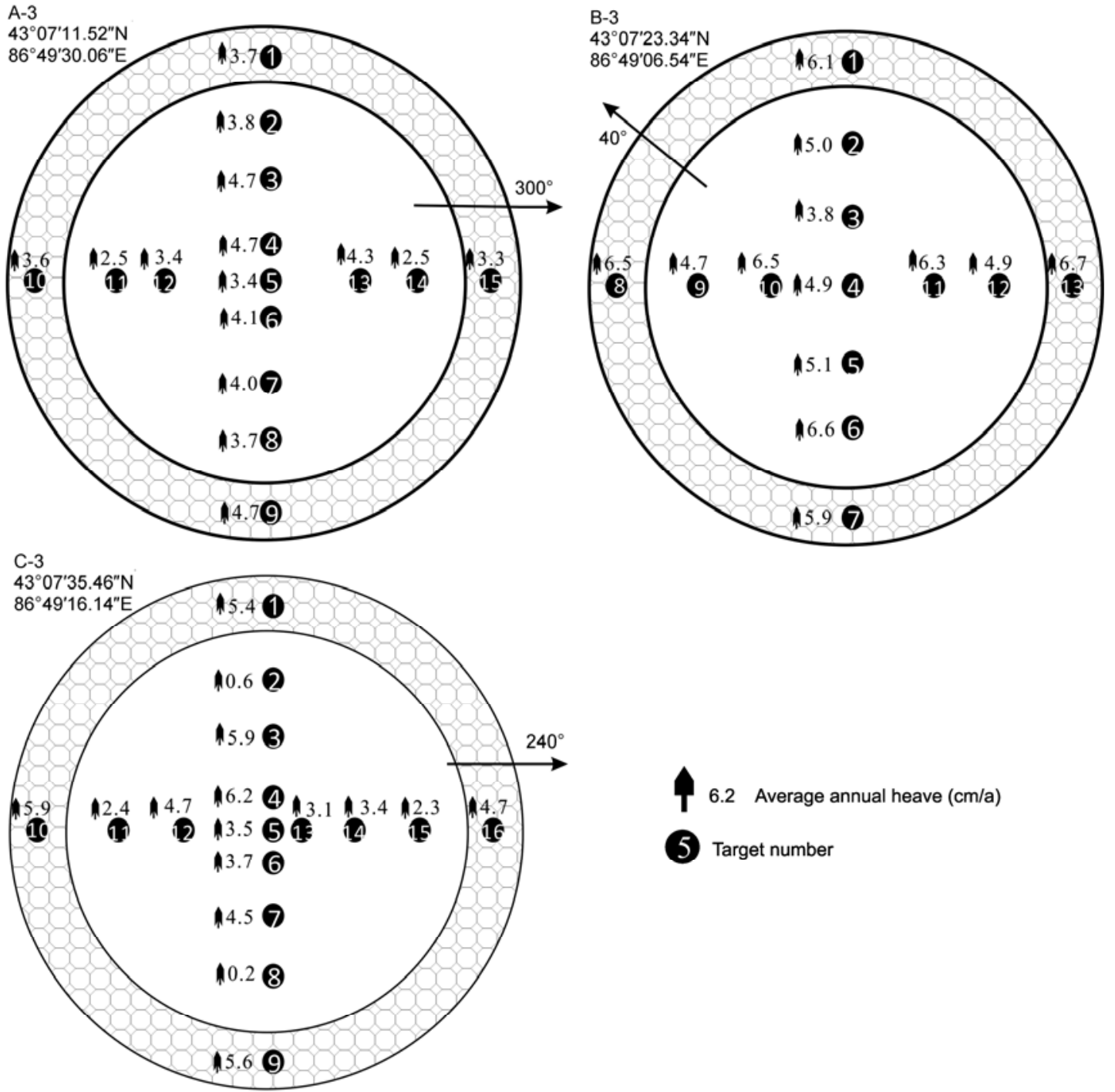

6.2 Average annual heave (cm/a)

(5) Target number

Figure 2 The layout of the targets (the diameter of sorted circles is about $2 \mathrm{~m}$ ). 
Table 4 Upfreezing of different groups

\begin{tabular}{llcl}
\hline \multirow{2}{*}{ Group } & \multicolumn{3}{c}{ Average annual heave (cm/a) } \\
\cline { 2 - 4 } & A-3 & B-3 & C-3 \\
\hline Central & 4.1 & 4.9 & 4.1 \\
Inner & 4.0 & 5.4 & 4.6 \\
Outer & 3.1 & 5.3 & 1.4 \\
Marginal & 3.6 & 6.3 & 5.4 \\
\hline
\end{tabular}

main mechanism of upfreezing must be different. Cui et al. [24], and Liu et al. [21] measured thirty-five sorted circles in Dry Cirque, and found the center mainly comprised by finer material $(<2 \mathrm{~mm})$, and some scattered gravel $(2.5-12$ $\mathrm{cm})$. The border was comprised of bigger gravel (3.5-17 $\mathrm{cm}$ ), and according to their pitting, the depth of coarse border is about $35 \mathrm{~cm}$. We speculate that the targets heaved mainly by frost-pull in fine center and frost-push in coarse border. In fine center, the distance an object moves depends on the frost heaving strain in the soil, the strength of the adhesion of the object to the freezing soil, and the style of collapse. In coarse border, the distance an object moves depends on push by ice lenses, and during freezing the objects are hindered as their remaining cavities would tend to be narrowed by frost thrusting.

\section{Discussion}

In the Dry Cirque, there are three obvious sorted circle zones, which are named as observation sites $\mathrm{A}, \mathrm{B}$, and $\mathrm{C}$. As the observation of cross-targets undergoes no interruption from 1991 to 2011, data continuity is good. Analysis of their changing trends is credible. For site A-3, there is an overall downward trend of the annual average upfreezing height from 1991 to 2011 (Figure 3), indicating that the effect of upfreezing is weakening and the activity of sorted circle is gradually degenerating. In addition, in our field survey, we also found the sorted circle shape was not distinct and had vegetation on it (Figure 4). For site C-3, there is an overall upward trend of the annual average upfreezing height, illustrating the strengthening activity of the sorted circle. In our field survey, we also found the shape of the sorted circle was distinct, the sorting was good and there was no vegetation present. For site B-3, the upfreezing height is relatively greater than those at A-3 and C-3, and it also shows a greater inter-annual fluctuation. The shape of the sorted circle was distinct and the sorting was better than that at site $\mathrm{C}-3$. The annual average heaving heights of targets at B-1 are the greatest at every depth, followed by those at C-1 and A-1 (weakest). The annual average heaving heights of targets in different diameters at B-2 record the greatest, followed by C-2 and A-2 (weakest). This indicates that $\mathrm{B}$ undergoes the strongest activity of sorted circles, while A undergoes the weakest, as upfreezing is the main performance of activity of sorted circle. Generally speaking, the inter-annual fluctuation of the activities of sorted circles at the three observation sites are consistent with peaks in 1999, 2002-2003, 2007, and 2010 respectively (Figure 3).

The annual average heave height of targets highly reflected the strength of the upfreezing in the area. Higher heaving of the target indicates more intense upfreezing, and the intensity of the upfreezing is often directly associated with the climate. Thus, we conducted a correlation analysis using the annual average temperature and annual average precipitation of the Dry Cirque in the source area of the

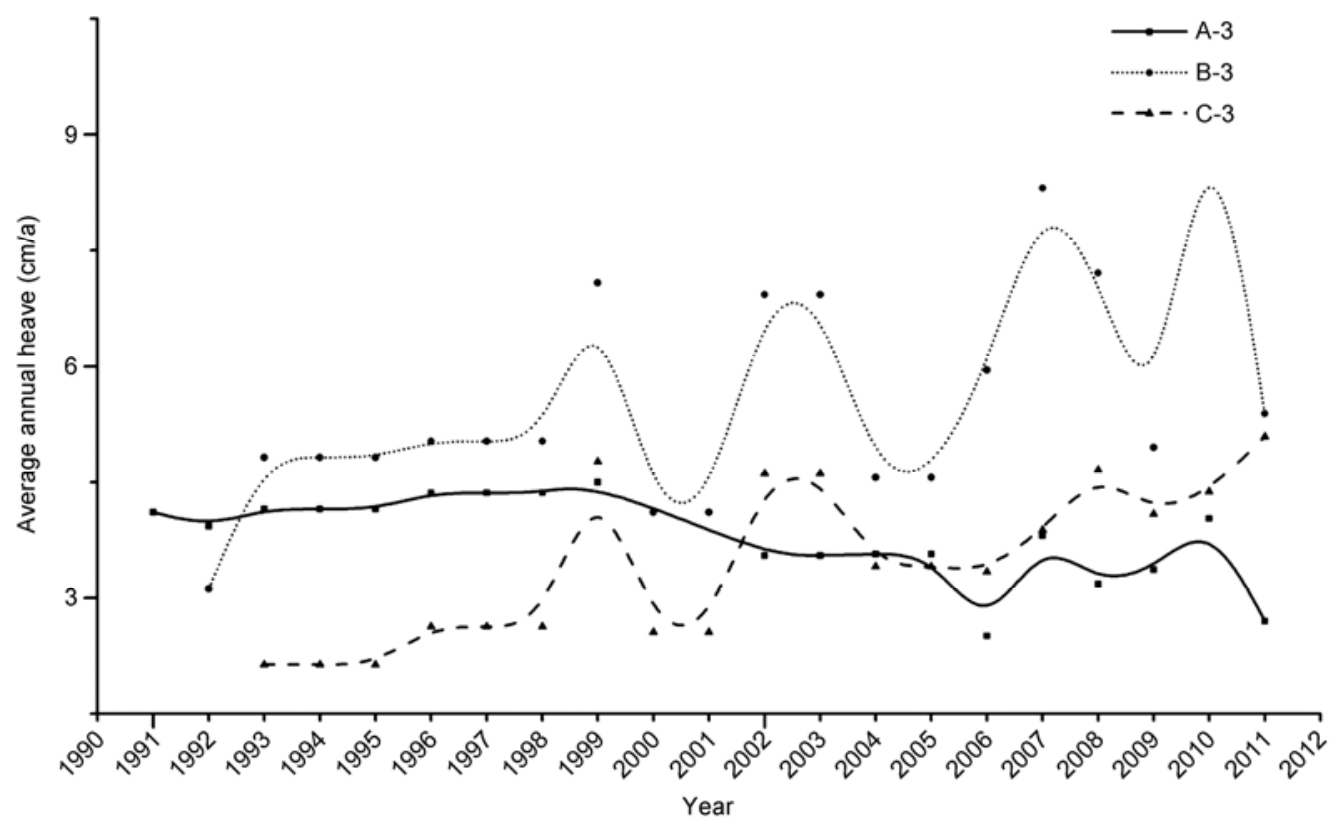

Figure 3 The trend of average annual heave height. 


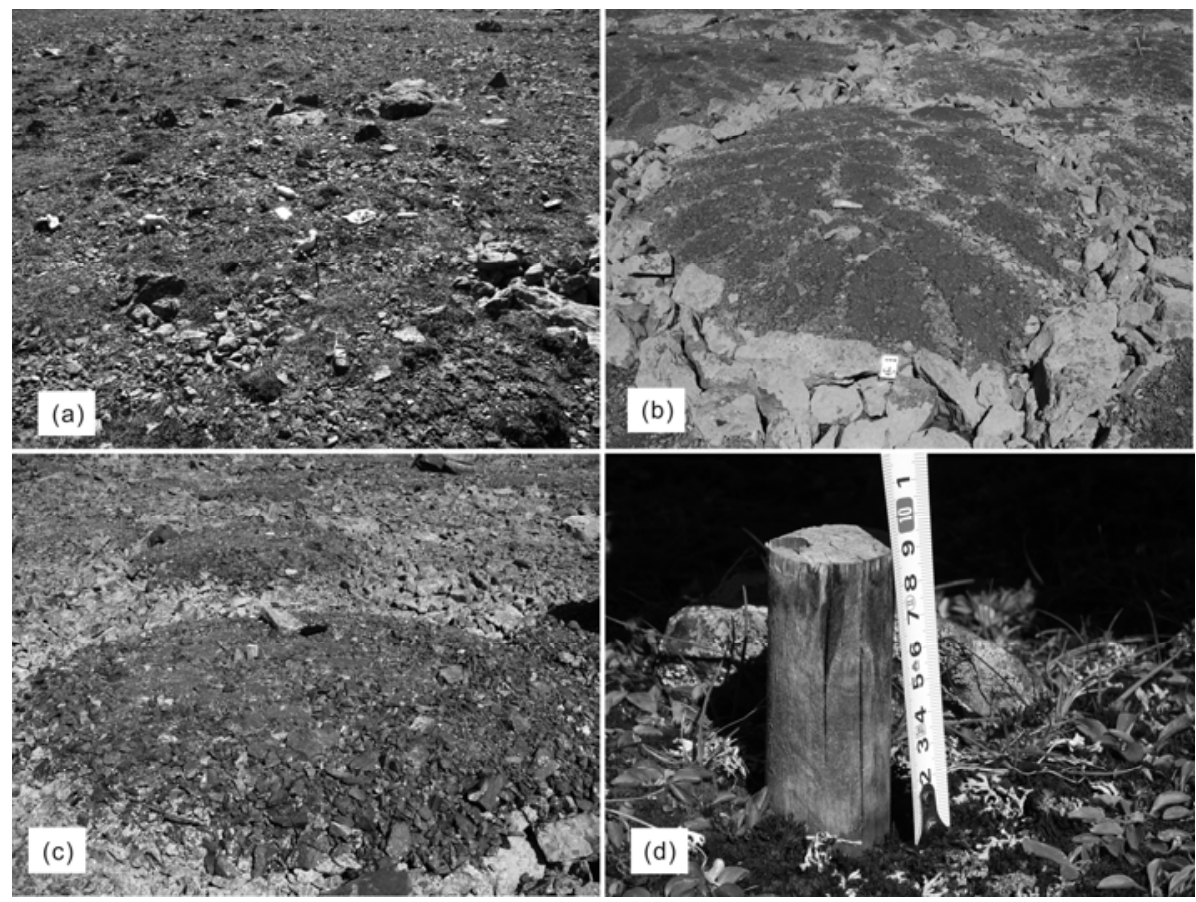

Figure 4 The morphology of sorted circles in site A (a), site B (b), site C (c), and target (d).

Urumqi River (data from the Tianshan Mountains Glaciological Station, both from September to next year August) and the complete annual average upfreezing height data of the cross-targets at B-3 as variables (Table 5).

Since the binary variables cannot truthfully reflect the common relationship in some cases, the partial correlation analysis was used in these instances. The partial correlation analysis is a method where when two variables are related

Table 5 Meteorological data of research area and B-3 annual average height of heave

\begin{tabular}{cccc}
\hline Year & $\begin{array}{c}\text { B-3 average } \\
\text { annual heave }(\mathrm{cm})\end{array}$ & $\begin{array}{c}\text { Annual average } \\
\text { temperature }\left({ }^{\circ} \mathrm{C}\right)\end{array}$ & $\begin{array}{c}\text { Annual average } \\
\text { precipitation }(\mathrm{mm})\end{array}$ \\
\hline 1992 & 3.12 & -6.7 & 409.3 \\
1993 & 4.82 & -6.3 & 427.4 \\
1994 & 4.82 & -6.5 & 459.8 \\
1995 & 4.82 & -7.1 & 367.6 \\
1996 & 5.03 & -7.3 & 484.5 \\
1997 & 5.03 & -5.9 & 303.0 \\
1998 & 5.03 & -5.2 & 420.1 \\
1999 & 7.08 & -5.2 & 454.2 \\
2000 & 4.11 & -6.7 & 486.6 \\
2001 & 4.11 & -6.2 & 353.4 \\
2002 & 6.93 & -6.0 & 458.1 \\
2003 & 6.93 & -6.3 & 371.9 \\
2004 & 4.56 & -5.7 & 352.1 \\
2005 & 4.56 & -6.4 & 445.2 \\
2006 & 5.95 & -5.6 & 414.8 \\
2007 & 8.31 & -5.3 & 256.0 \\
2008 & 7.21 & -5.0 & 396.3 \\
\hline
\end{tabular}

with a third variable, the third influential variable is eliminated and the correlation analysis is conducted only between the other two variables, which truly reflects the correlation between the two variables. We use SPSS software to analyze the annual average temperature, precipitation and the upfreezing height, and concluded that the annual average temperature and the annual average heave height is positively correlated $(R=0.56, P=0.024)$, while the annual average precipitation and annual average upfreezing is not correlated $(R=-0.09, P=0.737)$. Thus temperature plays a decisive role in the process of upfreezing. However, the correlation between temperature and the intensity of upfreezing is not direct. According to Ji [16], the more frequently the temperature fluctuates around $0^{\circ} \mathrm{C}$, the more intense the upfreezing, which better allows for the development of the sorted circle. Statistics were used to determine the number of days which temperature fluctuating around $0^{\circ} \mathrm{C}$ in 1992-2008 (Table 6). However, we found that these days had actually decreased. Obviously, this is not the reason why the upfreezing enhanced. As the geology, topography, vegetation and soil conditions remained essentially unchanged over a short period time, we speculated that the cause of upfreezing enhanced in study area was most likely due to the increased soil moisture content. As can be seen from Table 6 , in study area the average relative humidity from May to August tended to increase, which confirms our speculation. The effects of global warming are very broad [29-33]. It is the general consensus that permafrost degradation is a cause of global climate change [25]. Within inland arid areas, climate transition caused by global warming enhances the activity of permafrost to a certain 
Table 6 Days of temperature fluctuating around $0^{\circ} \mathrm{C}$ per year $\left(\mathrm{DTF} 0^{\circ} \mathrm{C}\right)$ and average relative humidity from May to August (ARH)

\begin{tabular}{ccc||ccc}
\hline Year & DTF $0^{\circ} \mathrm{C}(\mathrm{d})$ & ARH $(\%)$ & Year & DTF $0^{\circ} \mathrm{C}(\mathrm{d})$ & ARH $(\%)$ \\
\hline 1992 & 136 & 63.25 & 2001 & 115 & 70.50 \\
1993 & 135 & 69.75 & 2002 & 117 & 75.50 \\
1994 & 118 & 65.25 & 2003 & 106 & 78.67 \\
1995 & 115 & 68.00 & 2004 & 132 & 71.75 \\
1996 & 102 & 68.25 & 2005 & 123 & 77.75 \\
1997 & 134 & 69.00 & 2006 & 124 & 73.00 \\
1998 & 119 & 76.00 & 2007 & 118 & - \\
1999 & 115 & 72.75 & 2008 & - & - \\
2000 & 108 & 76.75 & - & & - \\
\hline
\end{tabular}

extent. Shi et al. [34] believed that climate transition from warm-dry to warm-wet was occurring in Northwest China and the headwater of the Urumqi River is located in the significant transition area. And the climate transition is not an isolated phenomenon due to rapid water circulation driven by global warming [34]. The climate of study area is affected mostly by the westerly current coming from the Atlantic Ocean and the Arctic Ocean, and also partly from Indian Oceans. For example, the 1990s have been the warmest decade recorded in Indian Oceans. In addition, 1998 saw the strongest El Nino ever recorded. Many corals in this region bleached and subsequently died [35]. Evaporation of water is extremely high at this time. Bengtsson [36] estimates that with warming caused by a doubling of green- house gases, the water content of the atmosphere will increase by $15 \%$. Therefore global warming will increase the moisture in the atmosphere in Northeast China. In turn there will be a decrease in surface evaporation and thus leading to an increase in soil moisture, which will make the upfreezing of permafrost more intense.

The evolution of landforms reflects the climatic conditions to some extent. Through long-term observations and study, a better understanding of the mutual feedback mechanism between climate and landform can be acquired. According to meteorological data, the annual average temperature of the Urumqi River region has been on the rise since 1992, while the annual average precipitation has fluctuated normally (Figure 5). Through the year-round observation of

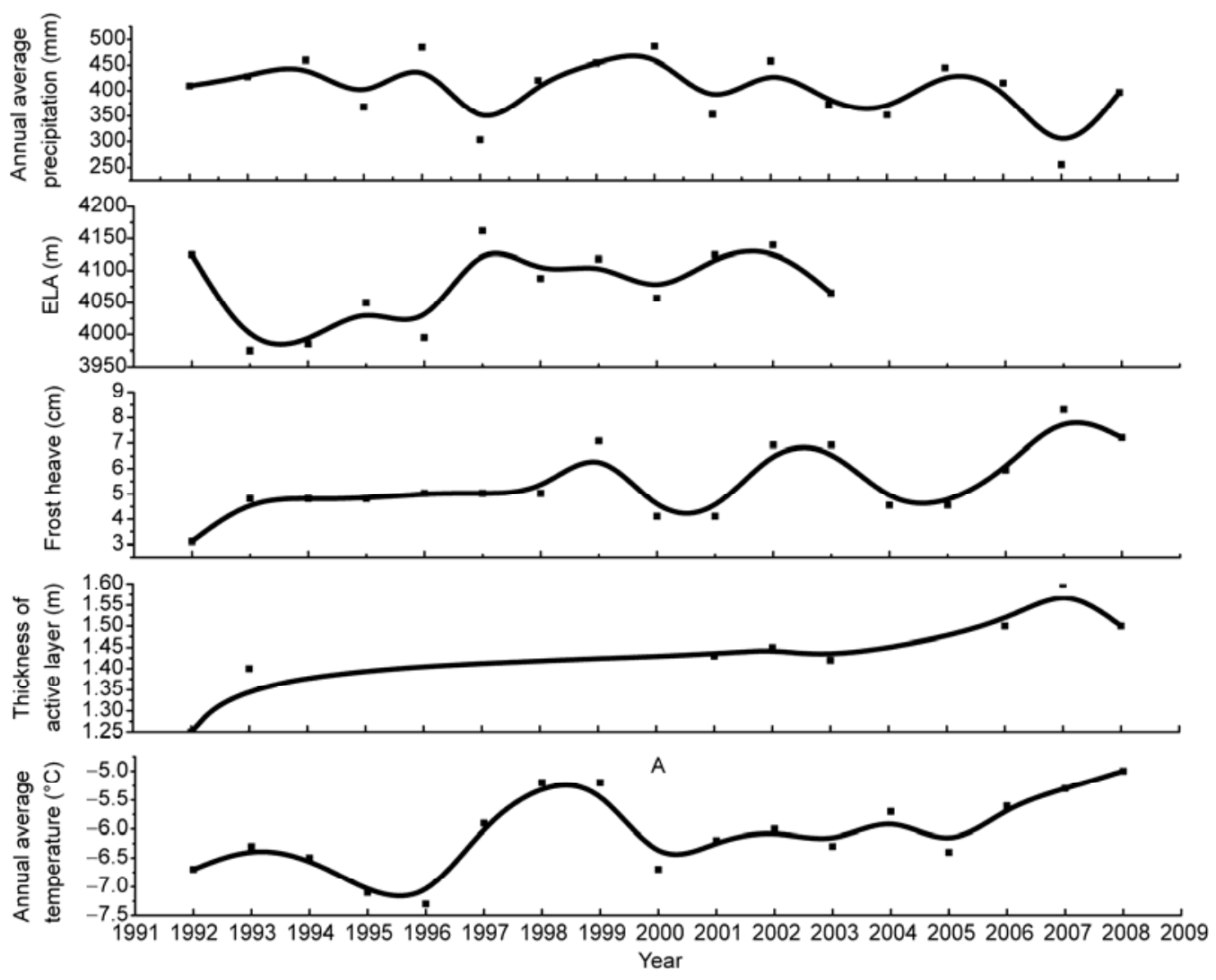

Figure 5 The relationship between climate and upfreezing of sorted circles, altitude of equilibrium line, and thickness of active layer. 
the sorted circle activity in the research area, a positive correlation between the sorted circle activity and the temperature within a certain range was found. The glaciers are also very sensitive to the climate change. Tianshan Mountains Glacial No.1 is located in the research area. The altitude of its equilibrium line fluctuates in a wide range, but the overall tendency is increasing [37], and it demonstrates a positive correlation with the temperature change. The active layer lies above the permafrost layer, which characteristically undergoes freezing in winter and thawing in summer, is also in a close relationship with climate change. From 1992 to 2008 in the research area, the smallest active layer thickness is $1.25 \mathrm{~m} \mathrm{[25]} \mathrm{and} \mathrm{demonstrated} \mathrm{a} \mathrm{clear} \mathrm{thicken-}$ ing trend, which responded to the temperature change.

\section{Conclusions}

Sorted circle is one of the typical landforms of the periglacial regions, which emerges in an active form or remains of that form. It can be used to infer past climate patterns can indicate small areas affected by climate change. Through the long-term observations of the geomorphology of sorted circles in the source area of the Urumqi River, in-depth knowledge of the activity mechanism of the sorted circle and its response to climate change was acquired. Conclusions are summarized below.

(1) In the source area of the Urumqi River, the intensity of upfreezing is the strongest within the topmost $25 \mathrm{~cm}$ near the surface. Among targets with diameters ranging from 1 to $5 \mathrm{~cm}$, those with a diameter of $3 \mathrm{~cm}$ are least affected by upfreezing. The difference between effects of upfreezing on the center with fine particles and the margin with coarse debris is not distinct within the same sorted circle.

(2) Sorted circles in Dry Cirques have different activity trends. The activities of sorted circles at the base of the back wall in Dry Cirque have become stronger, while those at the rock steps have become weaker and those in the center remain stable.

(3) Among the climatic factors, temperature has the most significant influence over the development of sorted circles and upfreezing. Global warming will increase the moisture in the atmosphere in Northeast China. It will in turn decrease surface evaporation and thus leading to an increase in soil moisture. The increased soil moisture will enhance upfreezing.

(4) Glacial and periglacial landforms are sensitive to climate change. Sorted circle activity, the altitude of the equilibrium line and the thickness of the active layer all positively respond to temperature increase in this region.

We gratefully acknowledge the help from Tianshan Glaciological Station, Chinese Academy of Sciences; and also thank Zhang Jingchun, Zhang Yue, Shi Lei and Fu Hairong for participating in field work. We thank the anonymous reviewers for their constructive suggestions that improved the manuscript. Also, we thank Sarah Beattie for polishing English. This work was supported by the National Natural Science Foundation of China (40971002 and 41101003).

1 Washburn A L. Classification of patterned ground and review of suggested origins. Geol Soc Am Bull, 1956, 67: 823-865

2 Washburn A L. Geocryology. London: Edward Arnold, 1979. 62-117

3 Ray R J, Krantz W B, Caine T N, et al. A model for sorted patternedground regularity. J Glaciol, 1983, 29: 317-337

4 Hallet B, Prestrud S A, Stubbs C W, et al. Surface soil displacement in sorted circles, western Spitsbergen. In: Proceedings of the Fifth International Conference on Permafrost. Norway: Trondheim, 1988. 770-775

5 Matsuoka N, Abe M, Ijiri M. Differential frost heave and sorted patterned ground: Field measurements and a laboratory experiment. Geomorphology, 1988, 52: 73-85

6 Bertran P, Klaric L, Lenoble A, et al. The impact of periglacial processes on Palaeolithic sites: The case of sorted patterned grounds. Quat Int, 2010, 214: 17-29

7 Matsuoka N, Abe M, Ijiri M. Differential frost heave and sorted patterned ground: field measurements and a laboratory experiment. Geomorphology, 2003, 52: 73-85

8 Grawe O R. Ice as an agent of rock weathering: A discussion. J Geol, 1936, 44: 173-182

9 Goldthwait R P. Frost sorted patterned ground: A review. Quat Res, 1976, 6: 27-35

10 Berthling I, Eiken T, Sollid J L. Frost heave and thaw consolidation of ploughing boulders in a mid-alpine environment, Finse, southern Norway. Permafrost Periclac, 2001, 12: 165-177

11 Matsuoka N. The relationship between frost heave and downslope soil movement: Field measurements in the Japanese Alps. Permafrost Periclac, 1998, 9: 121-133

12 Mackay J R, Ostrick J, Lewis C P, et al. Frost heave at ground temperatures below $0^{\circ} \mathrm{C}$, Inuvik, Northwest territories, Canada. Geological Survey of Canada Paper, 1979. 403-405

13 Mackay J R, Burrous C. Uplift of objects by an upfreezing ice surface. Can Geotech J, 1979, 16: 610-613

14 Jin H J, Qiu G Q, Zhao L, et al. Thermal regime research in upper source of the Urumqi River in the middle of eastern Tianshan (in Chinese). J Glacio Geocry, 1993, 15: 110-114

15 Wang G Y, Shen Y P, Mao W Y. Climate warming at headwater of Urumqi River, Xinjiang in past 44 years and its impact on glacier shrinking (in Chinese). J Glacio Geocry, 2005, 27: 813-819

$16 \mathrm{Ji} \mathrm{Z}$ X. The modern periglacial process in the central part of Tianshan Mountains (in Chinese). J Glacio Geocry, 1980, 2: 1-11

17 Cui Z J. Some progress in the research of periglacial landform in China (in Chinese). J Glacio Geocry, 1981, 3: 70-77

18 Liu G N, Xiong H G. The denudation rate of gelifraction and its influential factors in the periglacial environment of Tianshan Mountains (in Chinese). J Glacio Geocry, 1992, 14: 332-341

19 Zhu C. Some problems from the slope periglacio-landfrom on middle Tianshan Mountains (in Chinese). J Mount Sci, 1992, 10: 65-74

20 Zhu C, Cui Z J. The distribution and evolution of periglacial landforms in the source region of Urumqi River on the Tianshan Mountains (in Chinese). Acta Geog Sin, 1992, 1: 526-539

21 Liu G N, Liu Y F. Formation and distribution of the sorted circles at the head area of Urumqi River (in Chinese). J Glacio Geocry, 1993, 15: 474-480

22 Xiong H G, Liu G N, Cui Z J. Observation and research of sorted circles in Dry cirque at the head of Urumqi River, Tianshan Mountains, China (in Chinese). Geog Res, 1993, 12: 46-53

23 Liu G N, Xiong H G. Observation and consideration on the gelifluction in the Alpine periglacial environment of the Tianshan Mountains (in Chinese). Acta Geog Sin, 1994, 49: 363-370

24 Cui Z J, Xiong H G, Liu G N. The Geomorphic Process and Sedimentary Characteristics of Cryosphere on Middle Tianshan Mountains (in Chinese). Shijiazhuang: Hebei Science and Technology Press, 1998. 104-114 
25 Zhao L, Liu G Y, Jiao K Q, et al. Variation of the permafrost in the headwaters of the Urümqi River in the Tianshan Mountains since 1991(in Chinese). J Glacio Geocry, 2010, 33: 223-230

26 Schmid J. Der Bodenfrost als morphologischer Faktor. Heidelberg: Dr Alfred Hüthig Verlag, 1955. 144

27 Czeppe Z. Uwagi o procesie wymarzania głazów. Czasop Geogr, 1959, 30: 195-202

28 Bowley W W, Burghardt M D. Thermodynamics and stones. EOS Trans Amer Geophys Union, 1971, 52: 4-7

29 Shi Y F, Liu S Y. Estimation on the response of glaciers in China to the global warming in the 21st century. Chin Sci Bull, 2000, 45: $668-672$

30 Duan K Q, Yao T D, Pu J C, et al. Response of monsoon variability in Himalayas to global warming. Chin Sci Bull, 2002, 47: 1842-1844

31 Su M F, Wang H J. Decadal co-variability of the summer surface air temperature and soil moisture in China under global warming. Chin
Sci Bull, 2007, 52: 1559-1565

32 Li L J, Wang B, Zhou T J. Impacts of external forcing on the 20th century global warming. Chin Sci Bull, 2007, 52: 3148-3154

33 Fan D D, Liu K B. Perspectives on the linkage between typhoon activity and global warming from recent research advances in paleotempestology. Chin Sci Bull, 2008, 53: 2907-2922

34 Shi Y F, Shen Y P, Li D L, et al. Discussion on the present climate change from warm-dry to warm-wet in Northwest China (in Chinese). Quat Sci, 2003, 23: 152-164

35 Wilkinson C, Linden O, Cesar H, et al. Ecological and socioeconomic impacts of 1998 coral mortality in the Indian Ocean: An ENSO impact and a warming of future change. Ambio, 1999, 28: 188-196

36 Bengtsson L. A numerical simulation of anthropogenic climate change. Ambio, 1997, 26: 58-65

37 Li Z Q, Shen Y P, Wang F T, et al. Response of glacier melting to climate change (in Chinese). J Glacio Geocry, 2007, 29: 333-342

Open Access This article is distributed under the terms of the Creative Commons Attribution License which permits any use, distribution, and reproduction in any medium, provided the original author(s) and source are credited. 